\title{
BMJ Health \& Care Informatics \\ Mitigating staff risk in the workplace: the use of RFID technology during a COVID-19 pandemic and beyond
}

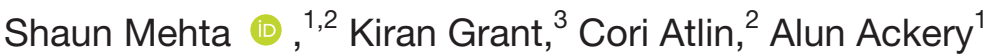

To cite: Mehta S, Grant $\mathrm{K}$, Atlin $\mathrm{C}$, et al. Mitigating staff risk in the workplace: the use of RFID technology during a COVID-19 pandemic and beyond. BMJ Health Care Inform 2020;27:e100230. doi:10.1136/ bmjhci-2020-100230

Received 31 August 2020 Revised 06 0ctober 2020 Accepted 02 November 2020
Check for updates

(C) Author(s) (or their employer(s)) 2020. Re-use permitted under CC BY-NC. No commercial re-use. See rights and permissions. Published by BMJ.

${ }^{1}$ Department of Emergency Medicine, Unity Health Toronto, Toronto, Ontario, Canada

${ }^{2}$ Faculty of Medicine,

Department of Emergency Medicine, North York General Hospital, Toronto, Ontario, Canada

${ }^{3}$ University of Toronto Faculty of Medicine, Toronto, Ontario, Canada

Correspondence to

Dr Shaun Mehta;

sd.mehta@mail.utoronto.ca

\section{INTRODUCTION}

Radiofrequency identification (RFID) technology uses electromagnetic fields to automatically identify and track tags attached to persons or objects to create a real-time location system. There are a variety of previously described use cases in healthcare that involve tagging patients, hospital personnel, medications and equipment in order to optimise clinical workflow and expenditure. ${ }^{1}$ In our opinion, such functionality can further be exploited to identify risks to staff safety and implement preventative mechanisms to address possible high-risk events through real-time alerts and accurate location information. $^{2-4}$ Furthermore, an increasingly pertinent application to mitigate staff safety risks involves the use of RFID tags to implement robust contact tracing programmes and ensure adherence to infection control standards during the COVID-19 pandemic. ${ }^{56}$

\section{WHAT IS RFID?}

Apart from the physical tags attached to persons or objects, there are a number of components including the antenna (detects the tag), the reader (receives tag information), the underlying communication infrastructure (enables RFID to interact with the informatics network) and the application software (figure 1). ${ }^{37}$

RFID devices can be subdivided according to whether they are active or passive. ${ }^{1} \mathrm{~A}$ passive tag has no power source; it is powered through interrogation by the RFID reader. Although the lifespan is long, this feature is a tradeoff for a short range of activity. An active tag, however, has an embedded power source that increases its operating rage, but the lifespan is relatively short between charges. A semiactive tag also has an embedded power source but is powered on by a trigger; therefore, these tags can conserve battery life and last longer than their active counterparts. As a general rule of thumb, passive tags are used for identification and active tags for tracking. ${ }^{1}$

\section{THE SIGNIFICANCE OF STAFF SAFETY}

Workplace violence is a ubiquitous issue across nearly all settings in healthcare and is on the rise. ${ }^{5}$ Studies from the emergency department (ED) literature report that up to $90 \%$ of healthcare workers have experienced some degree of workplace violence in the last 6 months, with nearly two-thirds feeling that violence is part of the job. ${ }^{8}$ RFID technology can augment current protective mechanisms by implementing real-time tracking and an emergency notification system. In addition, RFID tags could be deployed in potentially high-risk situations such as a hospital staff member working alone with a patient in an isolated area of the healthcare facility.

The vast majority of risk to staff safety is presented by patients $(89 \%)$, with family members, friends and colleagues making up the minority. Risk factors related to patients vary, but the most common characteristic is altered mental status, including dementia, delirium, an acute psychiatric illness or substance use. ${ }^{8}$ Other risk factors include long wait times, overcrowding, high-volume areas, low socioeconomic status of patients, inadequate staffing, working alone and a lack of means of emergency communication. ${ }^{9}$ In identifying scenarios that may pose higher risk based on historical or geographic factors, we can better identify staff who are at higher risk and equip them with RFID tags and the surrounding infrastructure to augment security staff response.

\section{WHY USE RFID IN THE PANDEMIC?}

Although several issues present safety risks to healthcare workers on a daily basis, at present, the largest risk is COVID-19. On 


\section{How does an RFID system work?}

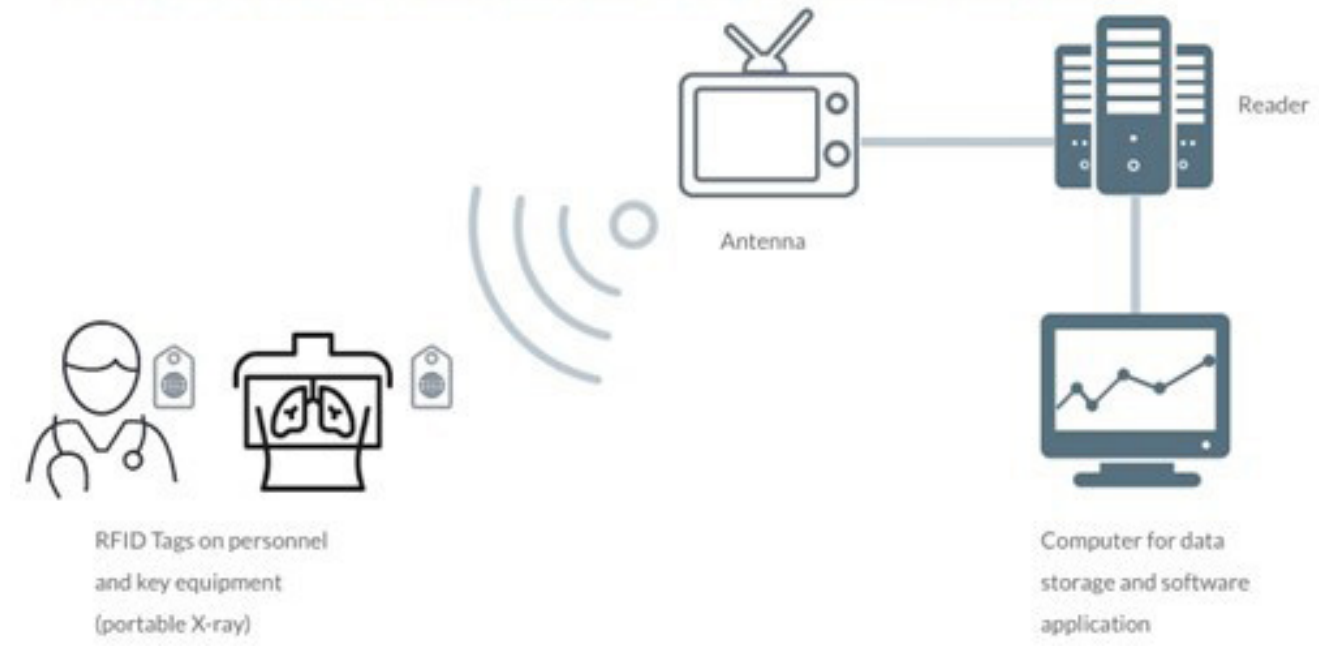

Figure 1 RFID system infrastructure. RFID, radiofrequency identification.

account of the virus's high infectivity and potential for asymptomatic transmission, as well as testing turnaround times creating a delay between patient encounter and lab confirmation, there is a critical need for robust contact tracing. Incumbent analogue measures are imprecise and arduous; thus, there is a role for RFID to provide a realtime system that can track all points of contact and can also be subsequently analysed to inform those who came into close contact with a known positive case (figure 2). ${ }^{5}$

For example, consider a patient in the ED who tests positive for COVID-19 2 days after presentation. With the use of RFID tags, each staff member that interacted with that patient (including but not limited to physicians, trainees, nurses, porters and custodial staff) could be identified, notified rapidly and sent for testing and/or isolation.

\section{WHO MIGHT BE ELIGIBLE?}

Determining which staff should receive RFID tags is an important discussion that must take place between all departments and receive buy-in from organisational leadership. In an ideal world, all staff and patients would be equipped with a tag; however, there are costs associated with an RFID infrastructure and so we recognise that institutions may not be able to purchase tags for everyone. While having only a group of staff equipped with tags may undermine the ability for accurate contact tracing, the development of an allocation scheme to prioritise those most at risk is prudent. It should be noted that incumbent systems for contact tracing can paradoxically increase cost given the significant human resource cost associated with it; therefore, a cost-benefit analysis case can be made in favour of RFID.

Creating an RFID task force consisting of members from different backgrounds (clinical, technological, administrative and so on) is a reasonable approach to ensure that all stakeholders' perspectives are included.
We suggest that a combination of evidence-based characteristics described in the literature (ie, risk factors for workplace violence and transmission of communicable disease) as well as hospital-specific data (code white activations, COVID-19 patient numbers and locations) should be used to determine which staff are most at risk. For example, an ED nurse interacting with a high volume of agitated and undifferentiated patients will inherently have a higher safety risk than a research assistant working in a non-clinical setting. Moreover, a hospital porter transferring patients around the hospital will have contact with several patients and staff compared with a radiologist that works out of their office.

\section{LIMITATIONS AND POTENTIAL HARM}

Using surrogate markers for staff safety-such as code white activations, critical incidents reports or COVID-19 cases-to inform RFID tag allocation may suffer from under-reporting bias and can underestimate risk for certain staff. Moreover, RFID tags should be deployed only to provide a means for staff to quickly identify themselves during a risky situation or to assist in contact tracing and so a comprehensive solution must further include a response team and policies.

With regards to COVID-19, components of an RFID system can fail and leave gaps in contact tracing, potentially missing staff who had an exposure. It would be dangerous to assume that RFID works flawlessly and give staff a false sense of security if they are not included in an outbreak notification. In addition, RFID tags are unable to specifically define how significant an exposure was or if personal protective equipment was used, and so there is an element of discretion required on the part of the interpreting team. There must also be processes in place to appropriately sanitise and turn over tags given that staff change over frequently. This presents increasing 


\section{RFID technology for contact tracing How RFID technology could enable real-time contact tracing of potentially exposed providers and contaminated equipment}

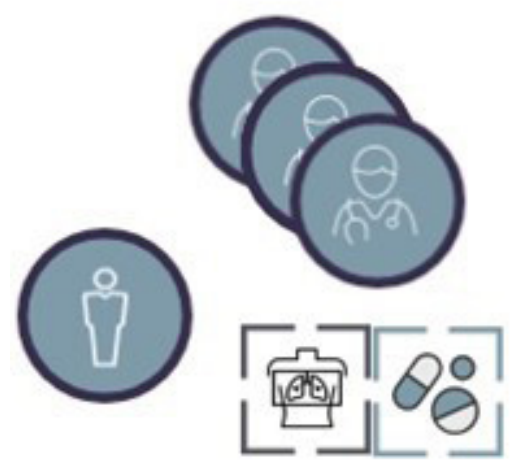

2. As the patient is assessed many different providers and pieces of equipment interact with them.

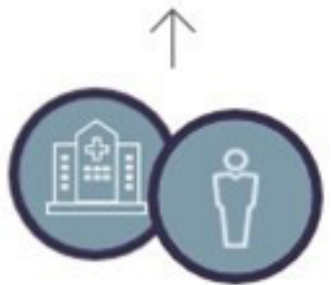

1. Patient presents to hospital.
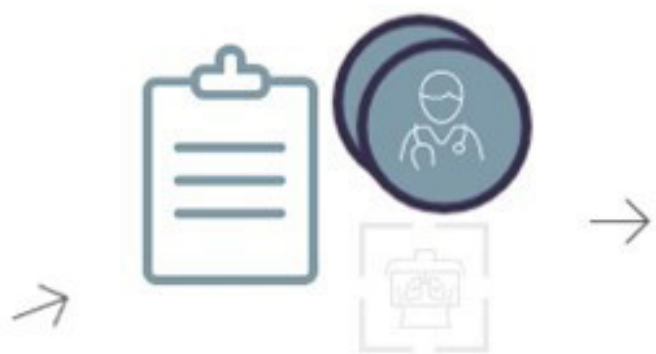

3a. Analog systems (pen and paper sign-in) rely on compliance from all staft, involve donning/dotfing PPE. and does not track equipment.
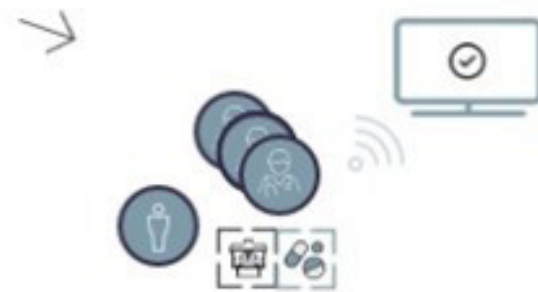

3b. RFID system is utilized enabling automatic hands-free tracking of personnel and equipment in real-time.

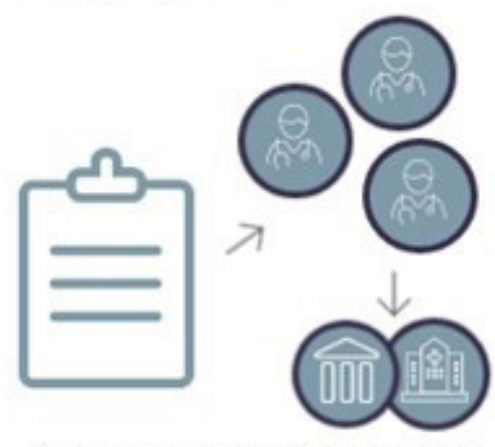

4a. In the event of an infection, records have to be manually reviewed and each provider individually contacted. No automated alerts at the hospital administration or public health level
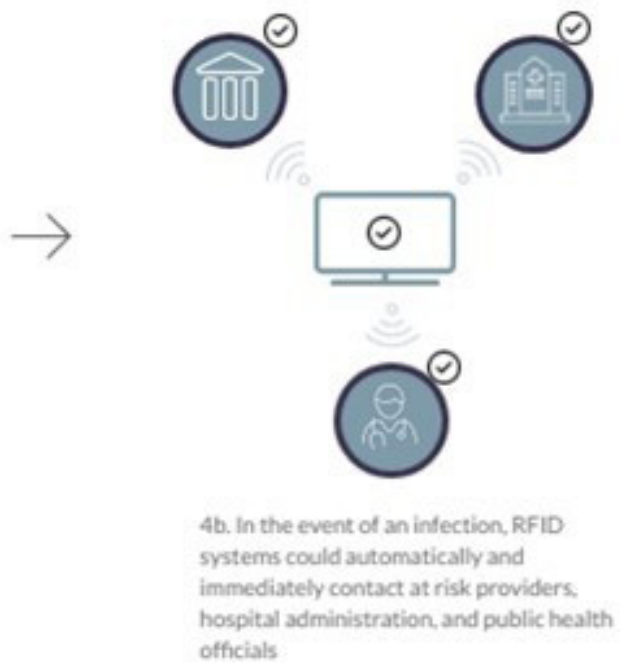

officials

Figure 2 Contact tracing using RFID technology. PPE, personal protective equipment; RFID, radiofrequency identification.

complexity in healthcare organisations where trainees, volunteers and other transient staff are included in an RFID allocation scheme.

There are reports of RFID technology systems interfering with the functioning of other hospital equipment. ${ }^{10}$ While additional iterations of the technology have attempted to address this limitation, all RFID systems will need to be rigorously tested in select hospital environments prior to a full implementation.

Significant concerns around staff privacy in any RFID system exist. ${ }^{11}$ The fact that staff can be surveilled at any time during work hours and that these sensitive data are vulnerable to cyberattacks is a major point of controversy. To mitigate these issues, several organisations are involved in developing standards for RFID technology, including the International Standards Organization and Electronic Product Code Global. Furthermore, the Information and Privacy Commissioner of Ontario has set guidelines for
RFID use. ${ }^{12}$ Nevertheless, any RFID allocation and implementation strategy should respect principles of privacy, consent and accountability. Safeguards must be created to ensure the protection of data, and where possible, data collection should be limited and deidentified in keeping with relevant privacy legislation. Data could also be stored locally within the hospital and not on a cloudbased platform where data breaches could happen. When engaging any concerned party, it may be helpful to frame the discussion of RFID tag use in terms of promoting staff safety as opposed to the observation and surveillance of staff behaviour.

\section{FUTURE DIRECTIONS}

RFID technology has successfully been used in many industries to improve efficiency and safety. Although significant logistical and infrastructure costs remain for 
RFID in healthcare, it offers an improved solution for staff and patient safety as well as infection control. Specifically, the use of tracking and alert systems can support the safety of healthcare workers in high-risk settings. Furthermore, as seen in recent studies on the management of infectious disease outbreaks including COVID-19, RFID technology has the potential to enable healthcare facilities to rapidly contact trace affected individuals. Future directions will include the implementation and subsequent evaluation of RFID tags as well as a cost analysis to determine feasibility and sustainability of such efforts.

Contributors KG, CA and SM wrote the manuscript. AA edited the manuscript and supervised as senior faculty and medical informatics director at St. Michael's Hospital.

Funding The authors have not declared a specific grant for this research from any funding agency in the public, commercial or not-for-profit sectors.

Competing interests None declared.

Patient consent for publication Not required.

Provenance and peer review Not commissioned; externally peer reviewed.

Open access This is an open access article distributed in accordance with the Creative Commons Attribution Non Commercial (CC BY-NC 4.0) license, which permits others to distribute, remix, adapt, build upon this work non-commercially, and license their derivative works on different terms, provided the original work is properly cited, appropriate credit is given, any changes made indicated, and the use is non-commercial. See: http://creativecommons.org/licenses/by-nc/4.0/.

\section{ORCID iD}

Shaun Mehta http://orcid.org/0000-0002-2111-167X

\section{REFERENCES}

1 Yao W, Chu C-H, Li Z. The adoption and implementation of RFID technologies in healthcare: a literature review. J Med Syst 2012;36:3507-25.

2 Lowery-North DW, Hertzberg VS, Elon L, et al. Measuring social contacts in the emergency department. PLoS One 2013;8:e70854.

3 Dufour J-C, Reynier P, Boudjema S, et al. Evaluation of hand hygiene compliance and associated factors with a radio-frequencyidentification-based real-time continuous automated monitoring system. J Hosp Infect 2017;95:344-51.

4 Cheng C-H, Kuo Y-H. RFID analytics for hospital ward management. Flex Serv Manuf J 2016;28:593-616.

$5 \mathrm{HJ} \mathrm{H}$, Zhang ZX, Huang Z, et al. Use of a real-time locating system for contact tracing of health care workers during the COVID-19 pandemic at an infectious disease center in Singapore: validation study. J Med Internet Res 2020;26;22:e19437.

6 Sharifian Z, Mansourian M, Rismanchian M. Feasibility study of using radio-frequency identification technology in estimating the time pattern of exposure to causative agents of occupational diseases. Advanced Biomedical Research 2018;7:135.

7 Ajami S, Rajabzadeh A. Radio frequency identification (RFID) technology and patient safety. J Res Med Sci 2013;18:809-13.

8 Phillips JP. Workplace violence against health care workers in the United States. N Engl J Med 2016;374:1661-9.

9 Copeland D, Henry M. Workplace violence and perceptions of safety among emergency department staff members: experiences, expectations, tolerance, reporting, and recommendations. J Trauma Nurs 2017;24:65-77.

10 Houliston B, Parry D, Webster CS, et al. Interference with the operation of medical devices resulting from the use of radio frequency identification technology. N Z Med J 2009;122:9-16.

11 Rosenbaum BP. Radio frequency identification (RFID) in health care: privacy and security concerns limiting adoption. J Med Syst 2014;38:19.

12 Canada O of the PC of. Radio Frequency Identification (RFID) in the Workplace: A Consultation Paper on Recommendations for Good Practices - March 2008 [Internet], 2008. Available: https://www. priv.gc.ca/en/about-the-opc/what-we-do/consultations/completedconsultations/rfid/ [Accessed cited 2020 Oct 4]. 